\title{
The Manuscript as Question: Teaching Primary Sources in the Archives-The China Missions Project
}

\section{Michelle McCoy}

\begin{abstract}
The collaborative effort between two Special Collections librarians and a history professor at DePaul University led to a quarter-long undergraduate project in the archives using China Missions Correspondence. In a reversal of traditional methods that assumes archival use to answer a question, this project looks at the document as the source of the questions. A qualitative analysis of student responses from these class sessions between 2002 and 2008 reveals the impact that direct experience has on primary source education and how outreach and user instruction in the archives can transform research, education, and the place of special collections within the institution. As a case study, this paper examines planning, administration, identification, instruction, and assessment of the project from the librarians' perspective.
\end{abstract}

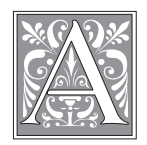

rchival collections provide tangible links to elements of history and society. These collections are unique clusters of letters, diaries, photos, memos, pamphlets, and many other documents that offer first-hand accounts of persons, groups, places, and/or events. Whether it is a word that is blacked out by a censor, a flourished cursive hand, doodles in the margins, or type that bears the soft purplish halos of an early mimeographed copy, the mere physicality of these documents exudes clues about the writer, the receiver, and the time period or the context. To interact with archival sources is an intimate experience; a sensation not captured through well-intentioned excerpts transcribed in textbooks. These materials in their original form have been long prized by history professors and archivists as the ultimate primary source due to their enormous potential for teaching students how to evaluate and interpret evidence. ${ }^{1}$

It is these very qualities that make the China Missions project at DePaul University so enticing for undergraduate instruction in historical concepts, methods, and materials. Born from a collaborative effort between librarians Kathryn DeGraff and Morgen MacIntosh Hodgetts and history professor Warren Schultz, the project contains critical elements beneficial to both parties. Since assuming leadership of the Special Collections and Archives department, DeGraff has been developing relationships with faculty and identifying

Michelle McCoy is the Bibliographic Assistant at DePaul University Special Collections and Archives and will graduate with her MLIS from Dominican University in spring 2009. She has undergraduate degrees in Art and Education. (CMichelle McCoy 
collections that could both cater to specific disciplines and fulfill the department's commitment to student education and use. ${ }^{2}$ Professor Schultz was interested in broadening the reach of primary source education by conducting a quarter-long project using original materials. ${ }^{3}$ The project's enduring success, as evidenced by student responses spanning 2002-2008, depended upon meeting numerous challenges, not the least of which was getting students past any initial skepticisms that can result from mentioning "missionary priests" and "China" in the same breath as "assignment."

Despite the wealth of literature surrounding student instruction with mainstream library resources, accounts and analyses from the perspective of librarians in Special Collections departments are somewhat scarce. Given the added considerations of handling unique and fragile materials, the guidance needed to provide first-time users the navigational confidence to locate materials with a finding aid, comparatively smaller departmental staffs, and the psychological barriers that many students face when confronted with reading rooms, rules, and noncirculating rare materials, more professional exchange is certainly warranted. The case at hand works through these inherent challenges as well as examining the larger organizational planning aspects of outreach, identification, administration, and assessment entailed in creating and hosting students for this quarter-long research project.

\section{Literature Review}

Since the time the China Missions project began in 2002, more case studies about class assignments in the archives began to appear. Most of these accounts were written by professors and published in educational journals. Little at this time has been written from the perspective of the Special Collections librarians. However, the educational literature is significant in that these cases outline the active learning and critical thinking components that were met as a result of an assignment in an archive or special collections setting. In addition, these success stories promote the desired faculty and librarian collaboration necessary to encourage further outreach efforts.

University of Colorado German professor Ann Schmiesing engaged with the Special Collections Department to specifically stimulate an active and collaborative learning environment where alternative sources could be employed in "student-directed exploration." ${ }^{4}$ English professor Carol A. Senf describes bringing her undergraduate Victorian studies class to the Special Collections Department as a means to encourage students move beyond their tendency to use "already digested" secondary sources that were often chosen without much thought. ${ }^{5}$ Senf also notes that archival sources can dramatically reduce plagiarism, since their individual nature means that secondary sources defining and analyzing a particular document are less likely to exist. ${ }^{6}$ Additional benefits of course projects conducted in the Special Collections, as detailed by history professor Marian J. Matyn, are an increase in the confidence level of student research and papers that are better informed and more engaging. ${ }^{7}$

In contrast to these testimonies, Kathleen D. Roe writes, "The general lack of understanding of archives is painfully evident to the archival profession. ${ }^{\prime 8}$ While Roe's article appeared in 1989, a qualitative study conducted by Elizabeth Yakel and detailed in her 2002 article "Listening to Users" suggests that this lack of understanding persists. ${ }^{9}$ Yakel interviewed a variety of individuals from undergraduate students to professional scholars. The findings reveal that many were uncertain if they had been to an archive or had used a primary source and that, even among more experienced researchers, the finding aid that maps the arrangement of an archival collection was often a source of confusion. ${ }^{10}$ To Yakel, the survey results indicated that, despite an increasing awareness of primary sources and their 
educational potential, archival organizational methods and the integral concept of provenance (or the actual "user" aspects) continue to be lacking from the instruction and in literature accounts. ${ }^{11}$ In other words, archival education falls short in an environment where the one-shot class session is the norm; and, for purposes of practicality, course relevant items are merely showcased as a means to create awareness and invite future use from the attending class. ${ }^{12}$

Nevertheless, class sessions in Special Collections are largely the result of partnerships and collaborations with faculty developed through the outreach efforts of librarians. Anna Elise Allison conducted a survey in 2005 of Special Collections departments with membership to the Association of Research Libraries (ARL) to assess the nature and extent of their user instruction. Of the respondents, 74 percent reported contacting faculty to develop instructional sessions with their classes. Allison's findings also indicate that 96 percent of the Special Collections departments participate in instruction sessions with undergraduates. ${ }^{13}$ Most of these sessions are course related and average about one hour in length, and only 20 percent "always" require an assignment within the collections. ${ }^{14}$ Allison's study also finds that, because professors have already identified course-relevant materials in conjunction with the Special Collections staff, less time is spent on how to find sources via the finding aids. ${ }^{15}$ The majority of class sessions with undergraduates are more or less orientations and introductions to the types of resources the facility contains.

Finding a diplomatic approach to meet the faculty expectations of course-related content and the special collections departmental expectations of educating students in how to access and use these materials is a challenge, particularly in the one-shot instructional model. A recent case study by Reynolds and Sauter ${ }^{16}$ combined the archive orientation with an assignment. While this case study specifically included information on how to use a finding aid, the students were also given a number of pregenerated examples of items that would be appropriate for their project. A decision was quite possibly made to facilitate a class where only so many original resources were available on the topic and all would be listed in the same finding aid. Nonetheless, as with Yakel's earlier contention, Marcia W. Keyser's findings suggest that, if the instruction process is not reinforced by actual student use, the exercise is diminished. ${ }^{17}$ In a follow-up article to her previous findings about user knowledge in the archives, Yakel further points out that, without more studies and assessment from these archival instruction sessions, we cannot fully appreciate which aspects of the instruction were the most helpful to students as opposed to the most interesting. ${ }^{18}$

A 2001 symposium, "Building on Strength: Developing an ARL Agenda for Special Collections," focused on how to determine and improve the directional course of special collections in research libraries including collaborative educational opportunities. From the working notes, Robert L. Byrd writes:

Other types of assignments - choosing and editing a document from a pre-selected group of manuscripts, writing a brief interpretive essay or assessment about a primary document or text, and so on-serve the purpose of putting the students in touch with primary sources and providing them with opportunities to develop their analytical and interpretive skills. ${ }^{19}$

Thus, a challenge was put forth to rethink the traditional models where a researcher comes in to answer a question or where a selection of materials is displayed for students with the hopes that their interest would be piqued. Fully engaging students requires more actual use, and that use is equally effective when it stems from a different formula. 
The majority of literature written on archival instruction makes note of one or more potential barriers to student use. Sutton and Knight note that, of the 4,000 undergraduate students at the University of the Pacific, only about 125 in a typical year receive a Special Collections orientation, thus leaving a significant number unaware of the department's existence, let alone its contents or their use. ${ }^{20}$ Greg Johnson, Professor and Archives Curator, discusses the additional levels of anxiety that students, particularly undergraduates, have about using materials that they cannot browse, that involve strange systems of organizations that are not searchable by subject, and that restrict them by numerous rules and regulations. ${ }^{21}$ Kathleen D. Roe notes that there is a perception that outside of advanced scholarship, archives are merely a "curiosity." 22 Schmiesing and Hollis concur that, too often, Special Collections departments have been wrapped in the aura of being resources only for serious researchers and not for students. ${ }^{23}$ Educator Katherine R. Morgan opens her case study by noting the common misperceptions of primary sources as "stale ideas of moldy texts on brittle paper." ${ }^{24}$

To counter these image problems and overcome use barriers, Special Collections educators employ and recommend a number of strategies to be used in conjunction with each other. In "Introducing Undergraduate Students to Archives and Special Collections," Greg Johnson outlines such pragmatic methods as creating a welcoming atmosphere, explaining rules and procedures in the context of protecting rare and fragile materials, tailoring the presentation materials to student interest or to the needs of the class, and providing handouts to reinforce the lesson. Particular importance is placed on sessions that build in time for handson examination of the materials used in the demonstration. ${ }^{25}$ Sutton and Knight quote Harvard history professor Laurel Thatcher Ulrich's statement, “'Objectcentered lessons are most effective when students can do their own looking. '" 26
This hands-on concept seems to be a generally accepted practice nowadays. Allison's 2005 study found that 82 percent of responding institutions encouraged direct student examination of documents during the class session. ${ }^{27}$

When the aim is to entice future student use, sensory components should not be overlooked. Visual elements capture attention in the digital age, and Schmiesing also contends that a blend of illustrated and textual materials is an important means of engaging diverse learning styles. ${ }^{28}$ Robyns goes a step further by noting that "guided use" of actual materials empowers students to make their own research connections. ${ }^{29}$ To capture a sense of a personal and expert connection with archival materials, Sutton and Knight advocate building time into the presentation for the professor to relate a story or two about his or her own research experiences so that students will also connect use with a respected authority figure. ${ }^{30}$

\section{Background of the China Missions Project}

Although most of these articles were written after the China Missions project began, numerous strategies discussed and advocated were employed in the History 199 class sessions at DePaul's Special Collections. Since Kathryn DeGraff took over department leadership of the Special Collections and Archives at DePaul, she has augmented and transformed the collections toward student use to fulfill the departmental goals of supporting curriculum through positive and educational experiences with primary source materials. She stresses that relationship building with faculty is the key component of the department's outreach efforts. Most of these collaborations are one-session departmental introductions. They feature a selection of course-related materials and are conducted with the hope that, once students personally encounter these unique sources, they will be inspired to return to conduct their research. Nonetheless, all successful collaborative class 
sessions build goodwill and have the potential to encourage future faculty collaborations with loftier class use goals.

In 2002, Professor Warren Schultz approached the Special Collections department. He was preparing to teach History 199 Historical Concepts and Methods, a required class for history majors. His goals were several: "I wanted the students to work with original archival material, if possible; I wanted to introduce them to the time-honored practice of preparation of a critical edition of text, complete with annotations; I wanted, if possible, for the archive to have an international aspect." Schultz was also looking for a structured project so that these first-time archive users could be effectively guided through the principles and methods of historical research while actually using original materials in the archive. As a result of this meeting, DeGraff suggested several options, one of which was the China Missions documents that were part of a newly accessioned collection.

In 2001, the DeAndreis-Rosati Memorial Archives (DRMA) collections were transferred to DePaul University from St. Mary's of the Barrens Seminary, Perryville, Missouri, the Vincentian motherhouse of the Western Province of the Congregation of the Mission. Among the numerous boxes were jewels in the form of correspondence from missionary priests in China during the turbulent years of 19231952. In these letters, the priests described their personal experiences to the young confreres back at the Perryville seminary. Known as the Clet Correspondence Guild, the letter-writing campaign was meant to encourage interest in missionary work and to ease the homesickness of young priests serving in a foreign land. While these letters reveal a wealth of information about foreign missionary work, they also provide testimony and observations about everything from weather conditions to the purchasing of motorbikes to pivotal events in China's history, including the Nationalist Movement, the Sino-Japanese invasion, WWII, and Mao.
Schultz was particularly intrigued by the DRMA correspondence. Not only was it a good fit with his criteria, but he also noted that the English from that time period would reflect enough of an unfamiliar worldview to challenge today's students. His interest created the impetus to transform a collection into a class project. DeGraff characterizes three essential components in this transformation process. First, the right faculty member needs to come along with the need and desire to build a project from materials in the collection; second, a collection with "sources of potential interest" needs to be identified; and, finally, the right "attitude" or a way of perceiving that collection as a learning source is required. The DRMA accession met these sets of the identification criteria. Its China connection had elements of broad historical interest and included the international aspect desired by Schultz. The collection was large enough to effectively serve a class. From a preservation and conservation perspective, the overall collection was in good condition and could withstand the increased student use. In addition, the Vincentian Studies Institute's book, The American Vincentians, contained a chapter on the missions to China that could be used to lay the groundwork for approaching this collection.

The final part of transforming a collection into an educational experience involved visualizing how students could best be guided through the use of that material. Schultz structured an assignment in steps. He began by having students select a letter that they would transcribe and later annotate and build outward from. The transcription process approached traditional archival instruction from a different angle. Instead of having students use the archives to answer a question, the item in the archive itself would be the question to be answered. This provided the last piece of the equation: it rethought the student approach to the collection. By examining a letter, transcribing, annotating, and eventually building outward 
from the letter's content, the assignment created a manageable way for Schultz to monitor and assess student progress as they worked with the materials as well as a manageable way for the Special Collections department to facilitate the needs of these new student users. From these seeds, Schultz was able to build a quarterlong class project in the archives, and the China Missions project was formed.

\section{Department Preparation and Archival Instruction}

In the age of institutional assessment, developing programs that promote use like the China Missions project go a long way toward integrating the resources of the Special Collections department into the curriculum. To ensure departmental success in this project, MacIntosh Hodgetts immediately processed portions of the recently acquired DRMA collection. Successive classes have each progressively benefited from more processed material, enhanced finding aids, the identification of supplementary resources within DRMA materials, and the creation of auxiliary indices and glossaries that facilitated research.

Another strategy for success was to go beyond the Special Collections instruction session that all of the History 199 classes receive. In these basic departmental sessions, the students are oriented to the department and its available resources with a discussion on how collections are built, how the department's rules are a component of preservation for unique materials, and some direct exploration of selected items in the collection. And, to prepare for an intensive quarter-long assignment in Special Collections, Professor Schultz's History 199 class had an additional instruction session. This second one focused more acutely on the DRMA collection, how to use a finding aid, and other practical applications in the archives such as using out cards, requesting photocopies, and citing an archival document.

To further meet the Special Collections department's goals of teaching students how to use the archive resources, analyzing a historical document, and generating a positive experience among the students, several educational components mingled to create an inviting and open atmosphere. As the practical archival procedures were taught, Schultz would interject with research hints and anecdotes of his own research experiences, thus providing his professional expertise and insight to the process. To better establish the peer relationship with the materials, a student employee in the Special Collections department demonstrated the archival box out card procedures and how to handle the materials physically. The students were also given a tour of the closed stacks so that they might be able to better visualize how and where the materials were kept. Several students remarked that they particularly enjoyed this aspect of the instruction because they felt it provided a sense of how and where all of these "mysterious" boxes were kept. ${ }^{31}$ Photographs from the DRMA collection depicting priests in the 1940s wearing short-sleeved shirts while sitting on motorbikes provided another entry point to the DRMA collection. As confirmed by accounts in the literature, DeGraff is well aware that unexpected and nontraditional images can spark student curiosity and help to soften the anxiety of researching unfamiliar subjects.

Despite the additional instruction, the responses written into the student's papers reveal that a few students still felt an initial intimidation about coming to the archives for the first time to research the letters. Among the comments, students expressed they did not feel fully prepared to use the finding aid or know where to begin their searches. For many students, this was their first encounter with an archive and with primary source materials, an important consideration for instruction in Special Collections and a consideration that was greatly eased by the structure and content of Schultz's class. Many students also responded that MacIntosh Hodgetts and the Special Col- 
lections staff helped to put them at ease by taking the time to go through all of these procedures again and assist with finding materials. ${ }^{32}$ The students, however, were also required to elaborate on which research methods taught in Schultz's History 199 class were most helpful to their understanding and use of archival materials. From these responses, it can be concluded that the early confusion that they expressed about finding aids and material arrangement was resolved by the combination of Schultz's phased instruction in research methods and concepts and by the practice of actual use.

The phased approach to primary materials research methods designed by Schultz was instrumental to the overall educational experience and to the management of student use in the reading room. Each phase corresponded to the historical research methods and concepts that were covered in his class sessions. The first phase was to choose a letter and make an accurate transcription. In terms of archival use, this step involved students reading a lot of letters and familiarizing themselves with the finding aids and boxes. Schultz's next steps asked students to identify such elements as names, places, events, or terminology in their letter. The identifications were to be annotated and would provide the elements that could be followed to develop a paper that built outward from the letter's testimony; this was the third phase. For the archives, this meant that students would need to use these name, place, event, or terminology elements as a way to locate other relative materials, such as directories, logs, books, and/or other letters. The last phase was the creation and presentation of the complete process, an integration of the primary and secondary sources gathered to put the letter in both its local and broad contexts. By 2005, Schultz named each phase respectively: "Text as Artifact," "Text as Source," "People and Places," and "Research From the Ground Up." 33 No duplication of letters was allowed, and Schultz encouraged students to read as many letters as possible before choosing one, stressing that this was the best way to find one that most interested the student. ${ }^{34}$ The classroom instruction by Schultz instilled the strategic tactics and concepts for archival research that Special Collections departments do not have the luxury of teaching in a one-shot session. The student outcomes point to the success of this cooperative approach.

\section{Student Outcomes}

As part of the assignment, the students were also required to describe how they found their experience using archival materials and the various research methods they employed to create their papers. This self-assessment was written into the research papers, and a copy of every paper was deposited into the DePaul University Archives. A qualitative survey of these papers was conducted to assess their responses. Seven class sessions were analyzed from 2002 through 2008 for a total of 133 students. Among the data collected were the number of students who found the experience to be a positive influence on their outlook for both research and using the archives. A total of 118 students, or 88.7 percent, considered working with original source materials to be a rewarding experience. To combat against students who would be loath to admit otherwise on a graded paper, the papers were individually vetted by citation. Students who used a total of four citations or fewer or relied heavily on Wikipedia or other Web sources whose reliability cannot be verified were moved to a neutral position and not included in the positive total. While these 15 students may have felt that their experience was positive, their resulting paper fails to capture the object of the exercise or, as Professor Schultz so aptly remarked, "They don't have the leg work to match."

Another phenomenon that occurred in the student experience: a majority of them formed a bond with the priest who wrote the letter they chose. Upon analyzing numerous papers, this connection 
was so apparent that a second analysis of the papers was done to explore the pervasiveness of this empathetic connection. Within the papers, 94 students, or 70.6 percent, made telling statements regarding the priest's personal character, remarked sympathetically on the nature of his dilemmas, and/or sought out photos and other personal documents. Several students even requested photocopies of photographs to be used on the title pages of their papers. Direct quotes from student papers will be presented in the next few pages.

In addition to the positive results, there was a desire to assess the extent of archival and other materials consulted by the students over the course of the project.
The following chart is broken down by whether the sources cited were archival, secondary, reference, or other. The sources defined as "other" includes period maps and photos as part of the research analysis. These sources are, for the most part, archival sources as well. As a word of caution, there is no way to really know how many letters the students may have read or how many other DRMA materials were consulted, both in the letter selection process and to gain more information on their priest and his situation. Given that, the number of archival sources reflected in this graph were by necessity drawn from citations and show how many of these archival sources were actively integrated into the paper. The steady increase

\begin{tabular}{|l|c|c|c|c|c|}
\hline \multicolumn{7}{|c|}{ Average Number of Sources Used Per Student } \\
\hline Year & Archives & Secondary & Reference & Other & Footnotes \\
\hline 2002 Spring & 2.2 & 3.3 & 2.1 & 0.4 & 16.5 \\
\hline 2002 Fall & 3.8 & 3.6 & 2.6 & 0.2 & 24.9 \\
\hline 2004 & 5.5 & 4.9 & 2.6 & 0.4 & 27.4 \\
\hline 2005 & 6 & 7.4 & 1.9 & 1.7 & 32 \\
\hline 2006 Spring & 8.2 & 4.6 & 3.1 & 0.8 & 34 \\
\hline 2006 Fall & 9.8 & 5.7 & 1.9 & 1 & 47.1 \\
\hline 2008 & 11 & 4.2 & 2.2 & 1.5 & 39.4 \\
\hline
\end{tabular}

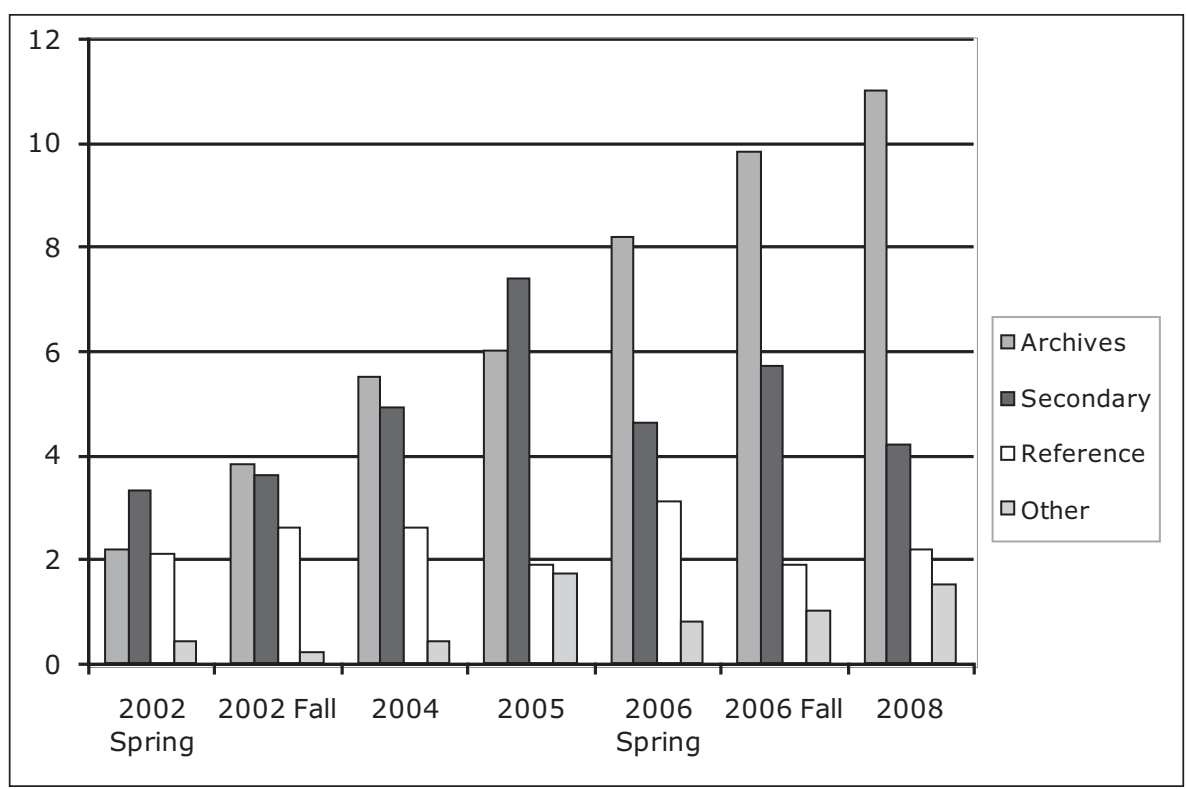


in the number of archival sources cited in the papers over the years indicates that, as more of the collection has been processed, both the department and Schultz have been able to better facilitate the sessions. This increase also reflects the subsequent processing of materials in the more than 25 linear feet of the China Missions collection. ${ }^{35}$

\section{Student Responses ${ }^{36}$}

"It was not until this project that I even knew there was a Special Collections department in our library." (2004)This is but one candid comment among the many reactions to using the archives. Another student referred to the archive resources as "...a diamond in the rough." (Spring 2002) In many instances, similar statements were seen over and over. Among the words expressed frequently in student reflections were "overwhelmed," "frustrating," "rewarding," "satisfaction," "puzzle," "detective," "time consuming," "new appreciation," and "fascinating." The following statements extracted from student papers aim to show a variety of the student observations and sentiments without being redundant. The comments have been broken down into three themes respectively: a general response to the archives and this project; a response to the archival research and retrieval processes; and, finally, statements that reveal a personal connection with the primary source materials. Below are the general responses:

It seemed like a daunting task.... Truth be told, I wasn't looking forward to spending many extra hours out of class researching something I did not know about and therefore did not care much about. However, I decided to stick with the class... and I quickly found myself having fun with the project. (2008)

...admitted lack of interest...What I found was that as I uncovered more information about the events and people discussed in my letter, the more fascinating those events became. (2008)

While doing the hands on research, I found everything to be of much more interest because it was real and important in some way. (Spring 2006)

This research process taught me to take a piece of historical evidence and build upward to a larger picture...While at times this project was frustrating and difficult it reinforced one of the most important attributes of a historian, patience and resilience. (Fall 2006)

I am sure that I did more research on this project, than any research I had done previously, and in a more professional and scholarly manner....In the end, my efforts in this project provided me with information and skills in researching that I will be able to apply to the rest of my life. (Fall 2006)

Never before have I worked so hard researching for a single paper and surprisingly enough I have never felt so involved and excited about one either. (Fall 2006)

One thing I will take from this course is that you don't know what you're interested in until you've researched it. (2005)

This exercise was unique in its use of primary documents and the discovery of other sources and research from the use of a single document provided a perspective that the "typical" research paper lacks. (2005)

It is important to realize that one single letter may have no importance at all, but when it is placed in an archive with many letters on the 
same topic, it becomes important as a piece of evidence. (2004)

Through this assignment I was able to feel like I was an acting historian trying to figure out a puzzle....I wish most of my papers were like [this] because you actually retain the information that you learn. (2004)

The assignment was not as painful as I imagined it. There was such a substantial amount of documents and helpful staff in the Special Collections department that made this assignment enjoyable. (Fall 2002)

In this exercise I was able to not only learn what doing history meant but I was also able to experience the “doing" process myself. (Fall 2002)

Wendy M. Duff and Catherine A. Johnson conducted a study of the archival research methods of historians in 2002. From this study, they were able to distinguish the following behaviors: orienting themselves to the collection, locating materials, filling in the contextual background, and determining what information is relevant. ${ }^{37}$ In discussing their findings, the authors note that working back and forth with background or contextual information is what allowed these historical researchers to determine the relevance of documents. Furthermore, having secondary information is critical to understanding how to use the finding aid most effectively. ${ }^{38}$ Guiding the students through this type of research was a core component of the History 199 class and Professor Schultz also required students to seek out secondary sources to help contextualize the primary source documents and determine their relevance.

This second set of student comments speak to how the students felt about conducting research in an archive and which research methods they favored or found useful. The four types of activities and the complexities of working back and forth with contextual information that Duff and Johnson describe are present in the student experience. Numerous students indicated that they felt "frustrated" at times and were uncertain how to know what sources were relevant. "Dead ends" is another student phrase to recur in discussing how they would arrive at a point where more information about a person or place could not be ascertained either in the archives or in secondary sources. Another student commented that finding a relevant source among all of the materials was "a gamble." (Spring 2006) Issues of time management become apparent in such comments as, "It takes a lot of time to go through books, atlases, letters, encyclopedias, dictionaries, journals" (2005) and "I became bogged down in research, obsessed with studying one subject." (2004)

Despite the acknowledgements that learning how to conduct research with original documents is a difficult process, these same students also expressed that they felt like a "real historian" and that, when the pieces came together, they felt deeply rewarded for their ability to resolve an issue. Each of these statements was chosen to provide insight into how first-time archive users work through and develop the research skills that often still challenge experienced historians. Their frustrations and observations can help to pinpoint how we approach reference services in a university archive setting.

The answers were not black and white. I couldn't just turn to a book to solve the problems presented in my letter. What I found interesting though was the fact that often when the [sic] I found a source of information on one aspect of my letter, that source led me to another solution. (2008)

It took a few weeks of working with the material before I began to feel a strong connection. The initial pitfalls or dead-ends...caused me to 
question my own abilities.... What I finally realized is that every topic, whether perceptually great or small, will always be subject to further inquiry....The evidence a researcher uses determines the validity of an argument a historian makes. (2008)

It [the letter] was one tiny piece to an immense and sophisticated puzzle. The letter itself is only a small three pages of worn paper, yet the information gained from it is expansive. (Fall 2006)

In doing context research, the sheer number of possibilities was daunting. (Fall 2006)

I was never aware of whether or not I had the right answer. (Fall 2006)

With most papers finding a few sources off the Internet would supply enough information to act like I knew what I was talking about. With this project it took a lot of in depth studying of materials. (Spring 2006)

I learned to be skeptical of sources. (Spring 2006)

[I]t was important to learn how to take good notes. (Spring 2006)

The thought that [a] secondary source existed because of primary sources never entered my mind prior to this assignment. (2005)

I was overwhelmed with the amount of information I was uncovering, but that helped me to realize the most important aspects of it and pull that together to tell a cohesive narrative. (2005)

The class held in the library was a good learning tool for the introduction to the special archives and library research; however, Inow wish that there was a session dedicated to helping us organize our findings and letters.... I am too stubborn to ask for help. (2004)

It was also frustrating because you can't read the liner notes or look through the table of contents to see if what you want is in the document you are looking at....I also learned in the archives about the infinite ways to spell names of places in China. (2004)

It [the assignment] is instead almost like a dinosaur being found. At first, you know you have something, but you don't know what it means or what it is entirely. But after brushing off the rocks slowly and methodically, everything begins to clear up and most of your questions start to be answered. (2004)

I created a typology of annotation to help organize everything that needed further investigation. This included identifying references to people, places, and events, foreign language terms, and other vocabulary. (2004)

I guess one of my greatest struggles was how to assess what was important. (Fall 2002)

The feeling of "a-ha!" that I experienced when finally finding what I was looking for and having my desk scattered with copies of letters that eventually came together like puzzle pieces made me feel like a "real historian." (Spring 2002)

Not finding what I was looking for taught me a valuable lesson. I think it is important to realize that often times, even though we do everything right we may still not find what we are looking for. (Spring 2002) 
The secondary sources helped me to better understand the topics written about in my primary source, and helped me to put the subject of the primary source into a more clear historical context. (Spring 2002)

The final area of student responses explores the bond or connection that resulted from using original source materials. One student called her experience "voyeuristic." (Spring 2006) This empathetic connection to the priest of their letters and other materials also directly corresponds to more comprehensively researched papers. The close association with the materials spurred the interest quotient of the students, thus driving them to know more about how this individual was affected by his contextual situation. For example, one student suspects that her priest was suffering from depression and took the time to carefully follow his actions and symptoms over several letters and compare them to those listed at Mayo Clinic. (Spring 2006) Another student notes the irony that his priest is "light and optimistic, and at times even funny" despite the miserable and trying circumstances in China at the time. (Fall 2006)

I have found that priests are simply like all individuals, they get scared and they get angry. (Spring 2006)

I could not help but become fascinated with some of the unquantifiable aspects of this Priest's life. Items such as personal letters to his mother, as well as pictures of the priest as he aged through life gave the process an intimate feel. (Spring 2006)

Furthermore, understanding the lifestyle and lives about the priests was surprising in itself, especially when the common assumption of priests are that they tend to be subtle and quiet, when these priests were actually interesting and had character. (Fall 2006)
I was moved by their [the priests] determination and selfless acts as Dunker and the others committed and risked their lives for the mission and for the people of China. (2005)

My favorite part of this assignment, in fact, was holding Father Misner's passport in my hands.... I began to think of him as an actual person and as a gateway to a broader lesson about the events that were going on at his time in history. (2005)

My initial analysis of the letter had not prepared me for the realization I had when one day during [sic] I thought to myself, these men are actually living under communist rule, and their lives were actually in danger. (Spring 2002)

\section{Conclusion}

As the educational literature discusses and the student responses confirm, using primary sources in an archive promotes creative and critical thinking skills, drastically reduces plagiarism, and produces more engaging papers. From an archives perspective, the undergraduate instruction and use is fruitful on multiple levels: it dispels anxiety about using different and noncirculating materials in the reading room; it reinforces the research practices with finding aids and the concept of provenance; it physically and emotionally connects students with history; and, not to be overlooked, it further integrates the resources into the curriculum as well as increasing the usage statistics of a department in an environment where quantifying your value and services has assumed increasing importance. Robert L. Byrd concurs: "In my experience, the key to eliminating, or at least decreasing, the marginalization of special collections has been active promotion of access to, and use of, those collections. ${ }^{39}$

The positive responses from the History 199 students imply that a significant number of them will return to a Special 
Collections and Archives department at some time in their future. The universal assessment tools currently being developed by the Archival Metrics Project seeks more systematic ways for repositories to track the user impact of their services both internally and against similar repositories. ${ }^{40}$ Nevertheless, rethinking how to use the materials for the purposes of education has expanded how the collections are viewed and how outreach might be approached with regard to both user instruction and faculty relationships. Analyzing how students respond to actual use of the materials in the capacity of a long-term assignment helps us to better understand why students describe feeling intimidated. Constance A. Mellon's pivotal study of library anxiety revealed that students often feel their search skills are inadequate from the start, ${ }^{41}$ and Carol Collier Kuhlthau's analysis of the research process revealed that that sense of anxiety extends to all phases of research paper creation. ${ }^{42}$ Combining these already present anxieties with "touching" unique materials and not feeling confident to use a finding aid or request an archive box only intensifies the initial encounters. Since actual research with archival materials has the potential to be both frustrating and deeply rewarding, user instruction sessions that also teach and reinforce the access tools and methods on the most practical levels go a long way toward helping to remove use barriers. However, the most effective component for success in the China Missions Project was faculty/librarian collaboration that worked in tandem to build the necessary understanding and skill sets in a structured format. If the goal is to create competent new users, guided use with solid methodology is necessary and faculty partnerships are the key to success.

\section{Notes}

1. Numerous authors from the archival and education fields emphasize this relationship between primary sources and history in particular. Among them, Marcus C. Robyns, "The Archivist as Educator: Integrating Critical Thinking Skills into Historical Research Methods Instruction," The American Archivist, 64 (Fall/Winter 2001) describes archives as a "laboratory of critical thinking" on page 373; and Wendy M. Duff and Catherine A. Johnson in their article "Accidentally Found on Purpose: Information-Seeking Behavior of Historians in Archives," Library Quarterly 72.4 (2002) state on page 473, "The heart of historical research involves the use of primary resources." See also: Julia Hendry, "Primary Sources in K-12 Education: Opportunities for Archives," The American Archivist 70 (Spring/Summer 2007): 114-29; Sharon Ann Cook, "Connecting Archives and the Classroom," Archivaria 44 (1997): 102-17; and Ken Osborne, "Archives in the Classroom," Archivaria 23 (Winter 1986-1987): 16-40.

2. Kathryn DeGraff (interview, July 11, 2008). All of the thoughts attributed to Kathryn DeGraff throughout this paper are as a result of this interview.

3. Warren Schultz (e-mail interview, June 3, 2008). Dr. Schultz stated, "In 2001 (I believe), the department voted to open up the type of major assignment the instructor could use in 199." History 199: Historical Concepts and Methods is a required course for history majors. All of the thoughts attributed to Warren Schultz throughout this paper are as a result of this e-mail interview, unless otherwise annotated.

4. Ann Schmiesing and Deborah R. Hollis, "The Role of Special Collections Departments in Humanities Undergraduate Teaching: A Case Study," portal: Libraries and the Academy 2.3 (2002): 470 .

5. Carol A. Senf, "Using University Archives to Demonstrate Real Research," Changing English, 12.2 (Aug. 2005): 297-98.

6. Ibid.

7. Marian J. Matyn, "Getting Undergraduates to Seek Primary Sources in Archives," The History Teacher 33.3 (May 2000): 354.

8. Kathleen D. Roe, "Public Programs," Managing Archives and Archival Institutions, ed. James Gregory Bradsher (Chicago: University of Chicago Press, 1989): 220.

9. Elizabeth Yakel, "Listening to Users," Archival Issues 26.2 (2002): 111-27.

10. Ibid., 116-18. 
11. Ibid., 119.

12. Ibid., 120.

13. Anna Elise Allison, Connecting Undergraduates with Primary Sources: A Study of Undergraduate Instruction in Archives, Manuscripts, and Special Collections (master's thesis, School of Information and Library Science of the University of North Carolina at Chapel Hill, 2005): 27. Available online at http://etd.ils.unc.edu/dspace/bitstream/1901/158/1/annaallison.pdf. [Accessed 26 July 2008].

14. Ibid.

15. Ibid., 33.

16. Matthew Reynolds and Dale Sauter, "Engaging Undergraduates in Special Collections Through English Composition," College \& Research Library News, 69.6 (June 2008): 318-21.

17. Marcia W. Keyser, "Active Learning a Cooperative Learning: Understanding the Difference and Using Both Styles Effectively," Research Strategies 17 (2000): 39.

18. Elizabeth Yakel, "Information Literacy for Primary Sources: Creating a New Paradigm for Archival Researcher Education," OCLC Systems \& Services: International Digital Library Perspectives 20.2 (2004): 62.

19. Robert L. Byrd, "One Day...It Will Be Otherwise: Changing the Reputation and Reality of Special Collections," RBM: A Journal of Rare Books, Manuscripts, and Cultural Heritage 2.2 (Fall 2001): 165 .

20. Shan Sutton and Lorrie Knight, "Beyond the Reading Room: Integrating Primary and Secondary Sources in the Library Classroom," The Journal of Academic Librarianship 32.3 (May 2006): 321 .

21. Greg Johnson, "Introducing Undergraduate Students to Archives and Special Collections," College and Undergraduate Libraries 13.2 (2006): 91-100.

22. Roe, "Public Programs," 220.

23. Schmiesing and Hollis, "Special Collections Departments," 465.

24. Katherine R. Morgan, "Using Primary Sources to Build a Community of Thinkers," English Journal 91.4 (Mar. 2002): 69.

25. Schmiesing and Hollis, "Special Collections Departments," 469; Sutton and Knight, "Beyond the Reading Room," 322; Robyns, "The Archivist as Educator," 374.

26. Sutton and Knight, "Beyond the Reading Room," 322.

27. Allison, Connecting Undergraduates with Primary Sources, 39.

28. Schmiesing and Hollis, "Special Collections Departments," 472.

29. Robyns, "The Archivist as Educator," 364.

30. Sutton and Knight, "Beyond the Reading Room," 322.

31. History 199, Student Papers, DePaul University Archives (2002-2008). Note: The student commentary referred to in this study was derived from the responses that students were asked to include in their course papers, all of which were deposited into the archives.

32. Ibid.

33. Warren Schultz, Associate Professor and Chair, Department of History, DePaul University, History 199 Course Syllabi, 2002-2008.

34. Ibid.

35. Finding Aids, DeAndreis-Rosati Memorial Archives. DePaul University Special Collections and Archives. Available online at http://library.depaul.edu/Collections/DRMA.aspx. [Accessed 17 November 2009].

36. History 199, Student Papers.

37. Duff and Johnson, "Accidentally Found on Purpose," 472-96.

38. Ibid., 490.

39. Byrd, "One Day...It Will Be Otherwise," 163.

40. Wendy Duff and Joan M. Cherry, "Archival Orientation for Undergraduate Students: An Exploratory Study of Impact," The American Archivist 71 (Fall/Winter 2008): 499-529. For more information on this project, see: http://archivalmetrics.org/.

41. Constance A. Mellon, "Library Anxiety: A Grounded Theory and Its Development," College $\mathcal{E}$ Research Libraries (Mar. 1986): 160-65.

42. Carol Collier Kuhlthau, "Developing a Model of the Library Search Process: Cognitive and Affective Aspects," Research Quarterly (Winter 1988): 232-42. 